\title{
Can Reserve Additions in Mature Crude Oil Provinces Attenuate Peak Oil?
}

\author{
Okullo Samuel Jovan, Frédéric Reynès
}

April 30, 2010

\author{
Institute for Environmental Studies (IVM) \\ De Boelelaan 1087, 1081 HV, Amsterdam, The Netherlands \\ okullo.samuel@ivm.vu.nl, frederic.reynes@ivm.vu.nl
}

\begin{abstract}
Following a peak in US crude oil production nearly 30 years ago, more and more non-OPEC producers have seen their production decline as a result of resource depletion. OPEC on the other hand has extracted a comparatively smaller proportion of its reserve base. Given that non-OPEC discoveries are growing ever limited, we explore the role of reserve additions and OPEC in determining future crude oil supply: we formulate a model that embodies a weak and strong OPEC for varied rates of reserve additions in mature crude oil provinces. Using this geo-economic partial equilibrium model that generates a peak in crude oil production, we show that although potential conventional crude oil resources may seem abundant, OPEC strategy could cause substantial crude oil reserve depletion in non-OPEC countries by 2050 (or even earlier) given likely depletion rates. In addition, we find that reducing reserve decline levels in mature crude oil provinces discourages OPEC from engaging in an overly strategic extraction behavior.
\end{abstract}

Key words: crude oil, reserve additions, inter-temporal maximization, strategic producers, OPEC

JEL codes: L13, L71, Q31,

\section{Introduction}

The debate on the availability of crude oil and generally fossil fuels has often been vehement between mainly geologists - e.g. Campbell and Laherrère [1998, Mohr and Evans 2007, 2008, and Hubbert [1956, 1962]] — who foresee an eminent peak in global conventional crude oil production (peak theorists) and economists - e.g. Lynch 2003,

\footnotetext{
${ }^{1}$ Conventional crude oil here refers to oil drilled by traditional oil well methods.
} 
Adelman and Watkins 2008 and O'dell 2004 — who predict that fossil fuel prices will re-adjust supply and demand so as to ensure their availability into the future.

In predicting oil2 supply, most peak theorists assume that crude oil production within a reservoir or a geologically homogeneous region can be approximated using a bell shaped curve, symmetric or asymmetric, e.g. the Hubbert curve. The assumption that a bell shape can correctly predict oil supply is based on the premise that oil production aggregated over a geologically homogeneous region initially rises slowly, and then increases exponentially, it reaches a peak then an inexorable decline starts thereafter $3^{3}$ - Beyond the peak, there is an immense difficulty for production to be increased as abundant and cheap reserves are not only lacking, but reserve additions are generally difficult to make. Historically, part of production data support this argument since many leading non-OPEC oil producing countries are experiencing declines in production and reserve levels amidst strong demand; the USA, Norway, the UK and Mexico are often cited.

Economists mainly, on the other hand, argue that there are flaws in the arguments forwarded by geologists about oil production. Not only have their predictions failed in the past, but will most likely fail in the future unless economic factors, for example those that affect a crude oil reserve base that they regard as fixed are included into their models [Cavallo, December 2004]. This reserve base, Lynch [2003]argues is not fixed and will continue to grow on the basis of increasing prices, improved information on geological endowment, and improvements in technology. Price increases and technology, will allow for the extraction of resources that were prohibitively expensive to extract at an earlier date. Even otherwise, Lynch 2003, p 22] states that in most cases, it is "demand [that] determines production, [and not so much the] geology."

In the oil industry, it is increasingly being recognized that a peak in global conventional oil production is inevitable by the year 2030. The IEA projects that global conventional oil production will either peak or plateau before the year 2030 unless investments are made in building capacity in OPEC countries [IEA, 2008]. In a 2009 report published by the United Kingdom Energy Research Council (UKERC), Global Oil Depletion: an assessment of the evidence for a near term peak in global oil production, it is noted that out of 14 contemporary forecasts of global conventional oil production, 9 models predict a peak in global oil production by the year 2030 whereas only 5 do not.

For this research, we do not to take sides on the debate of when global crude oil production will peak. Rather, we shed light on the amount of crude oil proven reserves

\footnotetext{
${ }^{2}$ Unless otherwise stated, oil in here refers to crude oil.

${ }^{3}$ The fall in production is often associated to declines in pressure within a reservoir (see: Cavallo December 2004]).

${ }^{4}$ Berg and Korte 2008 try to incorporate variables such as demand and reserve growth into their version of Hubbert model. They, however, find that the explicit inclusion of price is a daunting task. In an earlier paper, Pesaran and Samiei [1995] also find that although economic variables could significantly improve the performance of the Hubbert curve, the exact role of these variables in the methodology is unknown.
} 
required to meet global demand for oil from a geo-economic ${ }^{5}$ modeling perspective. We base the model on the assumption that although cumulative crude oil production is determined by ultimate recoverable reserves, the crude oil reserve build up proces: 5 , is much more important in determining and sustaining the year on year production. These additions depend not only on the long-term oil price, but also on the effort expended in drilling for such reserves, the reductions in cost, and current technology.

Furthermore, unlike some contemporary models of oil depletion that assume exogenous increases in OPEC production or do not take into account OPEC strategy, or assume that non-OPEC do not earn a rent on their resources but sell at marginal cost (see: e.g Greene et al., 2006, Brandt and Farell, 2009, Finn Roar Aune and Rosendahl, 2005]), we formulate a model that endogenously determines OPEC and non-OPEC output and price under different assumptions about the effectiveness of the OPEC cartel. We calibrate the model so as to capture strategic interactions between crude oil suppliers, by use of their market powers. We attempt to answer the following questions: What is the significance and role of OPEC producers in the oil production process? What level of reserve additions are required so as to ensure sufficient oil supply for the period under analysis (2005-2050), given OPEC strategy? Do reserve additions among non-OPEC producers affect the oil price differently as compared to reserve additions among OPEC producers, and if so, to what extent does this occur? What role could new oil producers have in determining the price oil?

In answering the questions above, we consistently study how oil production in Asia and the Pacific, Europe, and North America could evolve. We refer to these three regions as mature crude oil provinces because some of the following are attributable to their crude oil industry a) falling average size of discovery and development, b) declining production, c) falling reserve to production rations, and d) declining exploration interest Kemp and Stephene, 2005]. In addition, the present reserve to production ratios in these regions are very low and have has been consistently low. Investment in oil production in these regions could stabilize declines in non-OPEC oil production and would lower oil prices, as we have seen in the recent past. With time, however, such actions may lead to higher oil prices and increasingly shift the balance in global conventional oil production towards OPEC countries.

From the model we establish that approximately 1100-1300 bbls of crude oil are likely to be consumed between the years 2005 to 2050. Of this, OPEC production represents 45-50\%. Given that proven reserves at the end of 2008 were at approximately 1200 barrels of which OPEC possessed $80 \%$. There is no further elucidation required in pointing out that substantial reserve growth will be required in non-OPEC (more especially the mature regions) regions. Using the model, we establish that given OPEC strategy, reserve growth up to a factor of 3 will have to take place in some non-OPEC regions if a near-term peak in oil production is to be averted and prices are to remain relatively stable. We also find that because of a market advantage OPEC producers

\footnotetext{
${ }^{5}$ Here, geo-economic refers to economic opportunities for oil production given the geological constraints.

${ }^{6} \mathrm{We}$ also refer to this process as net additions/reserve replacement/reserve additions.
} 
Table 1: US oil reserve additions by category

\begin{tabular}{lcccc}
\cline { 2 - 5 } & $\mathbf{1 9 7 8 - 1 9 8 7}$ & $\mathbf{1 9 8 8 - 1 9 9 7}$ & $\mathbf{1 9 9 8 - 2 0 0 7}$ & $\mathbf{1 9 7 8 - 2 0 0 7}$ \\
\hline \hline New discoveries & $6.14 \%$ & $9.14 \%$ & $20.37 \%$ & $11.03 \%$ \\
\hline $\begin{array}{l}\text { Extensions and } \\
\text { discoveries in existing } \\
\text { fields }\end{array}$ & $28.71 \%$ & $29.60 \%$ & $41.16 \%$ & $32.45 \%$ \\
\hline Revisions & & & & \\
\hline Total (mn of barrels) & 25268 & 19281 & 17161 & 61710 \\
\hline
\end{tabular}

*Percentages may not add up to $100 \%$ due to rounding.

Source:EIA 2008

have, it is plausible that they will further hold back production for increased depletion in non-OPEC regions and as a result hasten a peak in global crude oil production rather than delay it is as often assumed. However, if OPEC members cheat on their quotas, i.e. the OPEC cartel is ineffective, then oil supplies may be augmented and a peak oil delayed, at least in the short term.

In the next section, we discuss the concept of reserve additions. Section 3 then, presents an oligopoly model for the production of oil while section 4 discusses the empirical calibration of the model. The algorithm used in solving the model and the scenario designs are discussed in section 5. Section 6 discusses the simulation results and section 7 concludes.

\section{Reserve additions}

Although oil extraction is often viewed as a process of reserve depletion and increasing oil prices, the search and discovery of new reserves customarily leads to additions to the pro oven reserves base, which in turn significantly affects crude oil prices USGS, 2000a. Additions to reserves occur when 1) new oil fields are discovered through exploration, 2) discoveries and extensions are made within existing fields, and also when 3) previously discovered resources are moved from the speculative category to the highly certain category (i.e. revisions).

Of the three, additions coming from exploration are the most dominant during the early phases of developing a crude oil region [Farzin, 2001]. They carry the highest risk, involve the more sophisticated technology and require heavy investment as new and more remote areas need to be drilled. Discoveries and extensions within existing fields, on the other hand, occur as a result of improvement in geological knowledge about the areas already under exploitation and growth in the oil recovery percentage within known wells USGS, 2000a. Revisions, like discoveries and extensions mainly occur when a field is already under exploitation . 
During the period 1978 to 2007, revisions accounted for $56.5 \%$ of US total reserve additions, and as can be observed in table 1, their percentage in the total additions has been falling over the sample period. In fact, during the period 1978-1987 as compared to 1998-2007, the level of additions from this source fell by nearly half in percentage terms and by more than half in volume (16,463 million barrels as compared to 6603 million barrels).

The USGS 2000b reports that with more and more crude oil regions in the world mature or being of mixed maturity, extensions and discoveries in existing fields and revisions will be expected to contribute the most to reserve additions. From table 1 however, falling volumes of extensions and discoveries in existing fields and falling volumes of revisions in the US bring into question the prospects for reserve additions satisfying an ever growing demand for oil since several other regions - e.g. Mexico, Norway, China, Ecuador, United Kingdom and some parts of Asia - are mature or are of mixed maturity.

For a period of 47 years (1961-2007), global crude oil production and net additions to proven reserves are shown in table 2. It is evident that during the period 2001 to 2007, crude oil production exceeded net additions to proven reserves by over 62 billion barrels; this is in contrast to the net additions in each of the previous sample periods which exceeded production by at least 20 billions barrels.

By group, although the sum-total for both OPEC and non-OPEC net additions was positive during the period 2001-2007, conventional oil producers; China, USA, Mexico, Norway and Canada who are among the leading non-OPEC conventional oil producers experienced negative additions to their proven reserve base (thus the negative percentages), i.e. they produced more than they could replace. Among the leading non-OPEC producers, only the Former Soviet Union (FSU) experienced positive net additions to their proven reserve base whereas within OPEC, the United Arab Emirates (UAE) did not make any additions to their proven reserve over the period 2001-2007.

Given that non-OPEC countries have consistently represented 50-70\% of global oil production, such declining trends in net reserve additions present dire consequences for the crude oil market. A failure by non-OPEC countries, more especially the mature regions to sustain a level of reserve additions that is commensurate with production in the near future could lead to declines in production that will be linked to a peak oil and high oil prices. To fully understand the consequences of such declines on production and price can only be fully understood through a modeling concept that takes into account prospects of reserve additions, demand growth, and the strategic behavior of crude oil producers.

\section{The model}

The model we propose is a game-theoretic Cournot-Nash, open loop, partial equilibrium model. It is game theoretic Cournot-Nash in the sense that production is based on 


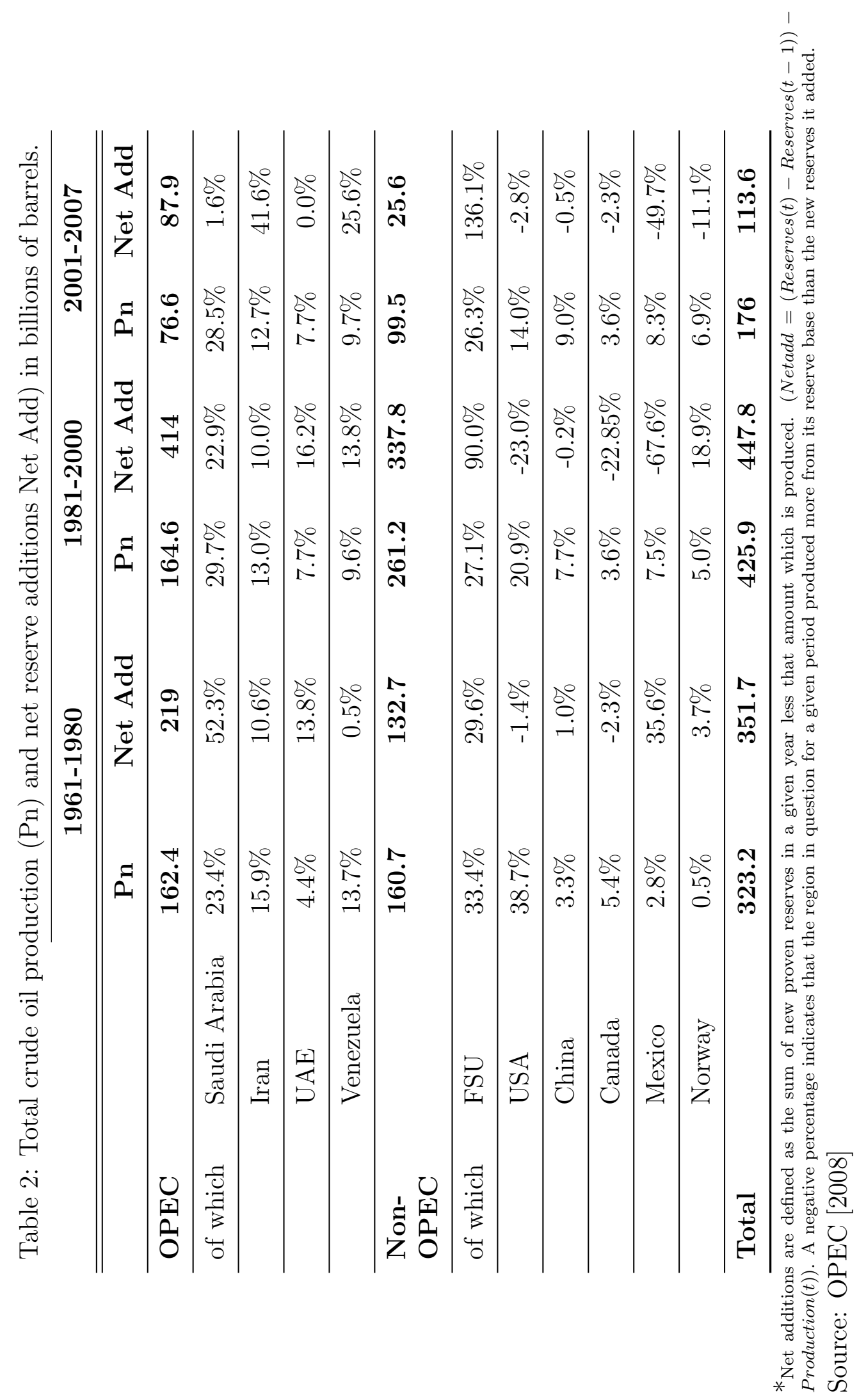


anticipations about other producers extraction trajectories. It is is open loop $]^{7}$ in nature because extraction trajectories are chosen in the initial periods and producers are not expected to deviate. And finally, it is a partial equilibrium model because demand clears supply on the assumption that prices from other sectors are constant.

Like Rehrl and Friedrich [2006], Greene et al. [2006], Brandt and Farell [2009]we assume that as reserves get increasingly depleted, reserve associated costs of extraction must rise. As a consequence, production at any one point in time will be influenced by the own state of resource depletion.

We also assume that strategic behavior substantially determines production at any one point time, in which chase, producers with a larger market power dominate the market as compared to small producers. Strategic behavior is mainly exercised by OPEC, while non-OPEC is assumed to be competitive (they have no market power) at all times.

To capture OPEC behavior, we assume like in Yang [2008] that OPEC producers may collude or compete against one other. When they collude, we refer to the cartel as OPEC effective (strong cartel) and when they compete against each other, we refer to the cartel as OPEC ineffective (weak cartel). Under effective OPEC collusion, members pool their production together; they appear to be one producer, and they extract under a new higher market power that guarantees them a higher mark up. Compared to Yang 2008 who represents OPEC as a single producer (social planner) 8 , we postulate that OPEC production is more appropriately determined through bargaining between members given the new higher market power. We therefore solve the model without having to reduce the number of players. In this way, we more suitable represent OPEC and avoid over extraction from a single deposit at the expense of another, as would be characteristic of a social planner with multiple deposits, more especially when deposits are of different cost: 9 .

When OPEC is ineffective, the producers no longer have the luxury of producing under a higher mark up, rather, they produce under their lower individual market powers. The implication of this is that members will extract more than when colluding ineffectively. This way of modeling allows us to mimic the cheating phenomena among

\footnotetext{
${ }^{7}$ An alternative would have been a closed loop model. In a closed loop models, producers update their extraction trajectories based on other producers conditions as the model is being solved. These practically relate to resource depletion problems; in some instances, however, closed loop models return the same solution as open loop models not withstanding that they would require assuming that one producers extraction is dependent upon other producers resource stocks. Empirical evidence in the literature that supports such an argument is hard to come by in the literature.

8 Yang 2008 also assumes that reserves do not affect cost. In our opinion, this could substantially influence the results as a constant present value shadow price (resource rent) is obtained if the the Hamiltonian is not a function of reserves (a state variable). Lin 2009 found that the resource rent is not constant but that it varies over time.

${ }^{9}$ Simulating the model before calibration shows that the social planner will initially extract more from the low cost deposit as compared to the high cost deposit. Modeling the players as independent but with a common market power as determined by the sum of their output, however, leads to initially higher extraction from the high cost deposit, total output is also initially higher and initial prices lower.
} 
OPEC, thus the term ineffective OPEQ10,

To represent the model, we adopt a Hotelling paradigm since it sufficiently characterizes the eventual exhaustability of the oil resource Yang, 2008]. In addition, it provides for a straight forward and concise framework to represent profit maximizing producers as we describe below.

Suppose that a country, $i$, is one of $\mathrm{n}$ oil producers in the global oil market who extracts an amount of oil $q$ in a period, $t$. And that the producer faces a cost $C(\bullet)$ that varies in the amount of oil extracted, the reserves, $R^{i}$, and in time, $t$, say due to technological progress. The producer's inter-temporal extraction ${ }^{11}$ problem - for $Y_{t}$ the income (Gross Domestic Product) of the oil consuming countries' - can be represented as:

$$
\max _{\left\{q_{t}^{i}, S_{t}^{i}\right\}} \pi=\int_{0}^{T}\left(P\left(Q_{t}, Y_{t}, t\right) q_{t}^{i}-C\left(q_{t}^{i}, R_{t}^{i}, S_{t}^{i}, t\right)\right) e^{-\delta t}
$$

st

$$
\begin{gathered}
\dot{R}_{t}^{i}=\left(\alpha_{t}^{i}-1\right) q_{t}^{i} \\
\alpha_{t}^{i}=f\left(S_{\tau}^{i}, X_{\tau}^{i}\right) \tau \leq t \\
R_{0}^{i}>0, q_{t}^{i} \geq 0, \alpha_{t}^{i} \geq 0 ; i=1, \ldots . ., n ; t=0, \ldots ., T
\end{gathered}
$$

where $P(\bullet)$ is the resource price, $S^{i}$ the efforts expended in building the reserve base and $Q_{t}$, the total amount of resource that is extracted at a time, $t . \delta$ is the discount rate, in which case preference is extended towards present consumption for more positive discount rates.

Equation 2 relates production to the resource resource base. It tracks the balance of reserves as a function of the reserve replacement rate, $\alpha_{t}$, and production, in which case, higher production levels lead to a larger growth in the reserve base. In fact, when reformulated, the equation states that reserves change as a proportion of production. Equation 3 describes the reserve replacement rate as a function of the effort expended in building the reserve base given that it get progressively harder to add to reserve as production cumulates. Equation 4 introduces the non-negativity constraints.

The rate of reserve replacement for a defined function can be greater, equal to or less than one. When the rate is greater than one, the reserve base grows, when equal to one, no resource depletion takes place and when less than one the reserve base gradually gets depleted. Typically the reserve replacement rate will vary over time and should tend to zero because of ultimate resource exhaustion. For most OPEC countries, $\alpha_{t}$

\footnotetext{
${ }^{10}$ Cheating occurs when OPEC producers producer above their allocated quotas

${ }^{11}$ We use the words extraction and production inter-changeably to mean the same thing.
} 
has in the past been greater the one, whereas non-OPEC countries have seen the their rates decline (see: 2).

In order to determine the optimal output and price, the set of equations in 1 and 2 for illustrative purpose we assume $\alpha_{t}^{i}=0$ - set is solved using the Hamiltonian - as shown in the Appendix - to obtain the first order condition:

$$
P\left(Q_{t}, Y_{t}, t\right)=\left(1+m^{i}\right)\left(C_{q}\left(q_{t}^{i}, R_{t-1}^{i} t\right)+\mu^{i}\right)
$$

where $m^{i}=\frac{\vartheta^{i}}{\left|\varepsilon^{i}\right|-\vartheta^{i}}$, for, $\varepsilon$, the price elasticity of demand $\left(\frac{\partial Q}{\partial P} * \frac{Q}{P}\right)$ and $\vartheta^{i}$ the share of producer $i$ 's output in total output $\frac{q^{i}}{Q}$. This relation indicates how important a firm's share of output is in influencing the resource market price.

In a perfectly competitive market $m^{i}$ will be zero since firms have neglible shares in production $\left(\vartheta^{i} \approx 0\right)$. In a market with imperfect competition $m^{i}$ will be greater than zero $\left(m^{i}>0\right)$ as a result of a mark up that is earned over price. Consequently, easticity must always be greater than a firms market share. This is straight forward to see in the case of a monoply in which case $\vartheta^{i}=1$ and as a result $\left|\varepsilon^{i}\right| \geq 1$.

Expression 5 requires that a producer $i$ extract at the point where the composite cost, $\left(C_{q}(\bullet)+\mu\right)$, scaled by a markup $m$ equates to the market price of the resource; which market price is also determined by other demand drivers: population size and the per capita income of the purchasing countries. Said differently, the producer's decision to extract will be determined by, own marginal cost, $C_{q}(\bullet)$; own marginal profit, $\mu$; own elasticity of output with respect to total output and the purchasing power of those who demand the crude oil. These four components, we find are essential for any model that attempts predict prices and supplies of crude oil because: (a) the marginal cost captures the cost producers face in extracting a resource, the higher the marginal costs of production the higher the price of oil; (b) the marginal profit captures the benefits that accrue from producing an extra barrel of oil for a given change in the price of crude oil: the higher such benefits are, the more likely it is for a producers to increase production; (c) the own demand elasticity captures the producer's ability to influence the price of the oil by simply decreasing output: the larger (smaller) a producer's output, the higher (lower) the increase in price and vice versa; and lastly, (d) the purchasing power as captured in the demand function indicates the strength consumers exert on the price of crude oil: the higher both per capita incomes and populations are, the higher the price and vice versa. 


\section{Model Calibration}

The functional form for the producers' cost function i: [2 $^{12}$

$$
C\left(q_{t}^{i}, R_{t-1}^{i}, t\right)=\Phi^{i} \frac{\left(q_{t}^{i}\right)^{2}}{\beta^{i}}\left(\ln \left(\left(\frac{R_{0}^{i}-R_{t}^{i}}{R_{0}^{i}}\right)^{-1}-1\right)-\alpha^{i}\right)
$$

It is driven by the 'own state of depletion, $\left(\frac{R_{o}^{i}-R_{t}^{i}}{R_{o}^{i}}\right)$, and the individual production level, $q_{t}^{i}$. Increasing production results into increasingly higher production costs and lowering reserve levels also increase the production costs, moreover in a logistic manner. Essentially the state of depletion depicts the notion that as more crude oil is extracted, reservoirs get progressively deeper requiring higher costs to extract the same amount oil. The cost function in expression 6 allows us to replicate the exponentially higher costs characteristic of resource depletion [see: Rogner [1997], Greene et al. [2006], and Brandt and Farell [2009]]. In the function, $R_{0}^{i}$ is the initial reserve level, whereas, $\alpha$, $\beta$ and $\Phi$ are parameters: $\alpha$ indicates how high one producer's costs are compared to another, $\beta$ indicates the rate at which costs increase as the resource gets depleted and $\Phi$ is a calibration parameter. We calibrate these parameters to empirical data for a selection of regions in the model by fitting the reserve associated costs of depletion to percentile cost data in Chakravorty et al. [1997] adjusted to 2005 dollars.

To capture the demand-price relationship, we assume an isoelastic demand function shown in equation 7. Compared to a linear demand function, such an isoelastic a function allows to easily study the properties of the model by varying some elasticities while keeping price elasticity constant. For instance, we can carry out a sensitivity analysis on income elasticity without having to worry that the price elasticity is changing.

$$
\left.Q_{t}=A Y_{t}^{(\eta * \omega)} P_{t}^{\varepsilon}\right)
$$

$A$ in the demand function represents demand for oil that is not affected either by income or price. $\eta$ is the income elasticity of demand for oil; it captures the effect of income on the demand for oil. $\omega$ is an energy efficiency factor in GDP which reduces income elasticity over time. We expect that as countries develop, the amount of oil used per unit of GDP falls. In most energy models, this energy efficiency indicator is introduced as an autonomous energy efficiency indicator (AEEI). The measure for income elasticity when used in such approaches is always constrained to one. For this investigation, we opt for an option in which the income elasticity used is as estimated in data, we then

\footnotetext{
${ }^{12}$ Note that which such a cost function, if reserves at $t$ exceed initial reserves, it is impossible to find a solution since the natural $\log$ is undefined for negative numbers. A simple correction can therefore be made: 1) restrict reserves at any point in time not to exceed initial reserves or 2) tweak the simulation program such that it will always select the minimum of the initial reserves or the current reserves.

From the reserve addition rates in table 3, we encounter such a problem with the Former Soviet Union(FSU). We decide to tweak the cost function in the simulation program, that way we also avoid a decline in the reserve associated costs of production for the FSU while other members costs increase due to depletion.
} 
build on the approach by introducing $\omega$, a factor which makes the elasticity fall over time. This allows for the introduction of energy efficiency into the model using methods more founded in economic theory Webster et al., 2008]. Finally, $\varepsilon$ which is the price elasticity of demand for oil measures the rate with which oil demand responds to changes in the price of oil. Global GDP data - at market exchange rate - for the period 20052014 is obtained from the IMF, these are then concatenated with projections from the US Department of Agriculture to 2030, after which, a growth rate of $2.7^{13}$ is assumed so as to prolong the data to 2050. This gives a GDP of 149 trillion dollars in 2050 which is comparable to projections in Poncet 2006

The simulation horizon for the model is 2100. In contrast, the reporting period is 45 years (2005-2050). We choose a simulation horizon of 2100 because it is the least time period for which a stable trajectory for crude oil extraction can be established for all players up to 2050. The reporting period of 45 years is chosen because of the current reserve to production ratio which is about 42 years. The 45 years allow us to easily compare current reserve holdings to cumulative oil production on both a player by player basis and at a global level as generated from the model.

Basing on the level of conventional oil production and export, the size of reserves, the geographical location of the oil producer and the most likely production policy, we come up with 11 oil producers: (1) OPEC 1 ${ }^{14}$ which consists of: Saudi Arabia, Kuwait and the United Arab Emirates(UAE) (2) OPEC II (Iran, Iraq and Qatar), (3) OPEC III (Libya and Algeria), (4) OPEC IV (Angola and Nigeria), (5) OPEC V (Venezuela and Ecuador), (6) NAM (United States, Canada, Mexico and Greenland), (7) ASP, Asia-Pacific, (8) LAM (Latin America excluding Venezuela, Ecuador and Mexico), (9) Europe (EUR), (10) The Former Soviet Union (FSU) and (11) OTMA which includes Middle East and Africa who are not members of OPEC e.g. Egypt, Mauritania, Chad, Oman, Syria among others.

For reserve additions, we consider three core scenarios. These scenarios are based on the redefinition of equation 3 as:

$$
\alpha_{t}^{i}=\left(\frac{\int_{0}^{\tau} q_{t}^{i}+R_{\tau}-R_{0}}{\int_{0}^{\tau} q_{t}^{i}}\right)
$$

With data on reserve to production ratios for 2007 and 2030, and reconstructed production data from 2007 through to 2030 from the IEA [2008] projections, we estimate the implied reserve addition rates for $0=2007$ and $\tau=2030$. We refer to these as the benchmark (BM) rates (table 3). As pointed earlier, the reserve replacement rate should in the ideal case vary over time, due to data limitations, however, we estimate a constant $\alpha^{i}$ for selected producers ${ }^{15}$. From these rates, it is clear that all regions with

\footnotetext{
${ }^{13} 2.7$ is also the average annual growth rate in GDP over the period 1975-2009 as estimated from the USDA data: http://www.ers.usda.gov/Data/Macroeconomics/.

${ }^{14}$ OPEC I countries, also referred to as OPEC core in Gately, 2004 often act in concert, they are considered to be price setting "swing" producers and are distinguished by their abundant oil reserves and relatively small populations.

${ }^{15}$ Due to insufficiently disaggregated data from the IEA 2008], we had to assume that some regions,
} 


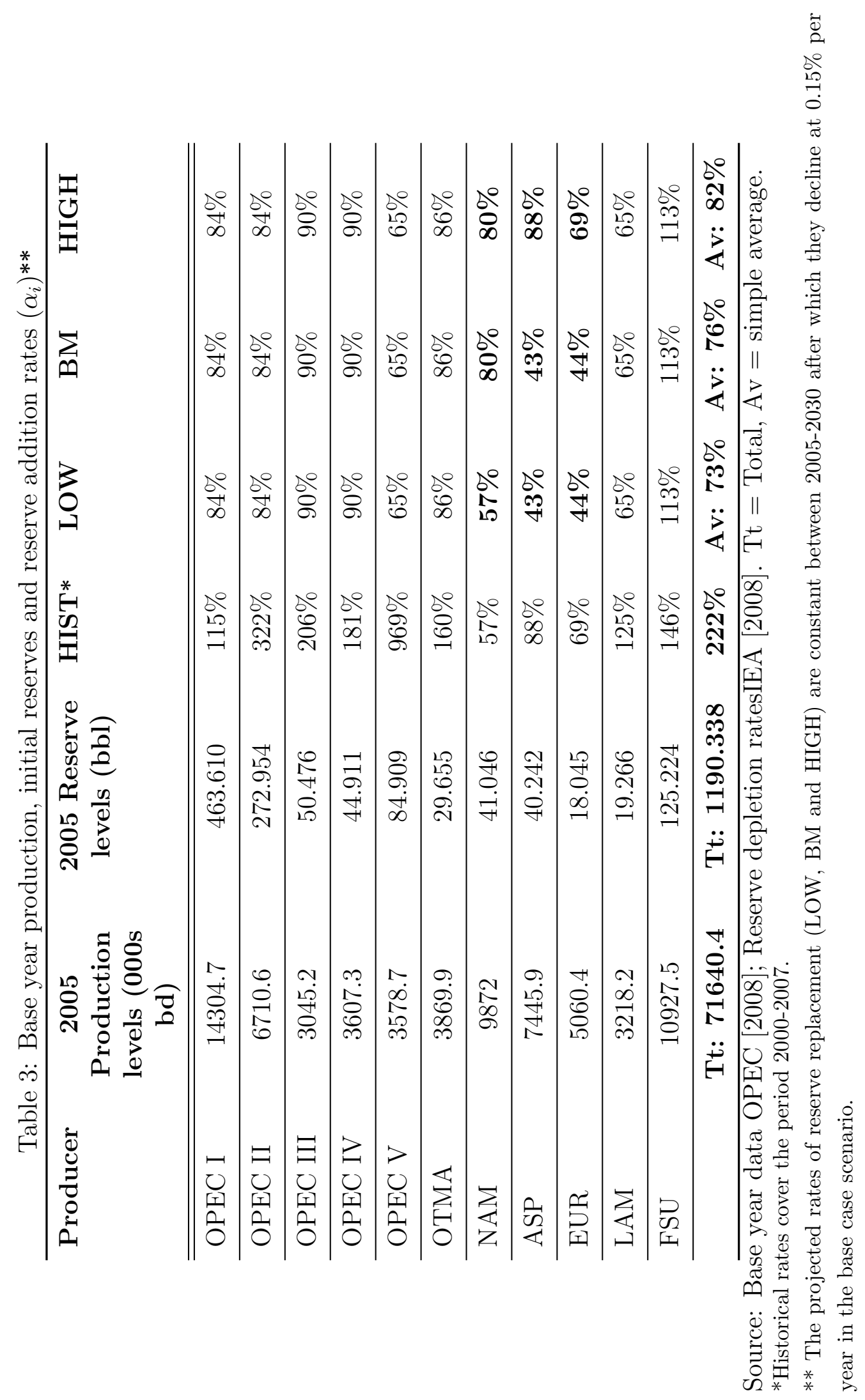


the exception of the Former Soviet Union are projected to undergo reserve depletion with Asia-Pacific and Europe facing the highest depletion rates. The IEA projects that Europe, Asia-Pacific and North America will see declines in their production over to 2030. The Former Soviet Union, on the other hand experiences additions to its reserves, mainly because of reserve growth in Kazakhstan.

From the benchmark and historical (HIST) rates (table 3) we infer rates for the other 2 core scenarios; the low rates (LOW) scenario and the high rates (HIGH) scenario. To obtain the low rates, we compare benchmark and historical rates for three regions: NAM, ASP, and EUR. We then select the lowest of the two rates and combine these three low rates with benchmark rates from the other regions to make up the LOW rates. Also in table 3 are the HIGH rates; these are inferred using the same procedure for the LOW rates except for the consideration of the higher rate of the HIST and BM rates for the three mature regions.

Historically, depletion rates have been highest in NAM, ASP and EUR. These regions have also represented a significant proportion of non-OPEC oil production. By considering a low rates scenario, we are looking at how a tightness in investment in the oil industry which results into less reserves, higher oil prices and probably lower global crude oil production could evolve. We also investigate the response that could be followed by either OPEC or other producers and the magnitude of their impacts on global oil production. We select the three core scenarios so as to present a succinct but comprehensive coverage of indicative reserve addition rates.

Since rates of reserve replacement will decline over time, we assume a simplification that the rates for each producer decline at $0.15 \%$ after 2030 . $0.15 \%$ was used by Höök et al. [2009] to illustrate how IEA [2008] projections change if variable rather than fixed field decline rate is used. We use this speed of decline so as to emphasize the impact of resource depletion for all players. Actual speeds of decline could be higher or lower and will tend to vary from producer to producer as determined by the maturity of the fields, the potential for resource growth and efforts in exploration. Nonetheless, the general notion is that once past peak areas with smaller offshore fields, such as the North sea, will have faster speeds of decline than areas with large onshore fields such as the Middle East.

In GAMS, the model set up as a Mixed Complimentary Program (MCP). MCP simplifies the study of different market structure assumptions i.e. strategic interactions between players such as different forms of collusion. The model is solved such that, for a given GDP projection and selected parameters, an equilibrium outcome for the oil price

e.g. OPEC I and OPEC II, had the same rates of additions. I.e. from the IEA 2008] we were able to infer data for eight regions whereas the model we estimate has got 11 regions (producers). We therefore had to assume that some regions shared the same rate of reserve additions. This is the case for OPEC and OPEC II, OPEC III and OPEC IV, and OPEC V and LAM, whose rates are for the whole Middle East, Africa, and Latin America, respectively. In some instances we had to combine two regions from the IEA 2008] so as to obtain rates for one region in our model. We did this for ASP and OTMA, in which case we weighted rates for Asia-Pacific, and Africa and the Middle East, respectively, by production over the projection horizon (2007-2030) 
and supply are obtained such that individual producers are not willing to deviate from their outputs. Given the open loop nature of the maximization problem, the solutions obtained are dynamically consistent (producers do not have the motivation to deviate from their production paths) and unique (irrespective of the order of players, the same solution is obtained).

\section{Results and discussion}

In presenting the following results, we assume a long run price elasticity in demand of -0.6 , an income elasticity of 0.8 and a base oil efficiency parameter of $0.4 \%$ per annum ${ }^{16}$ . For the discount rate, we assume a standard rate of $3 \%$ for all simulations. We report the results selectively concentrating the first part on highlighting strategic behavior as characterized in the model and the second part on analyzing the impact of strategic behavior and crude oil reserve depletion on future oil production.

We label the market structures as OPEC E and OPEC I for an effective and ineffective OPEC, respectively. Combining the market structure with a scenario for reserve additions, for example OPEC E and a LOW reserve replacement scenario, we come up with OPEC E: LOW which defines a complete base case trajectory for equilibrium resource extraction.

\section{Strategy in the face of depletion}

Although market share determines the influence that a producer exerts on the market and ultimately determines the the extraction trajectory in a given market structure, the ability for colluding firms to alter marginal profit substantially determines the equilibrium production and price trajectory across markets:

When colluding producers face no reserve depletion and no reserve additions $\left(\alpha^{i}=\right.$ 1 ), price and extraction trajectories are identical across the market structures. Colluding producers behave as though they are extracting from a renewable resource base since marginal profit is zero in both markets. With an inability to alter marginal profits from zero, colluding producers follow the same profit maximizing trajectory across the markets and as a consequence total production also stays the same.

On the other hand, when $\alpha^{i} \neq 1$ for colluding producers, their marginal profit is no longer zero. Production and hence price cannot be unique across the 2 markets; collusion will require increases in marginal profit leading the colluding producer to with hold production, thus increasing the market price. 


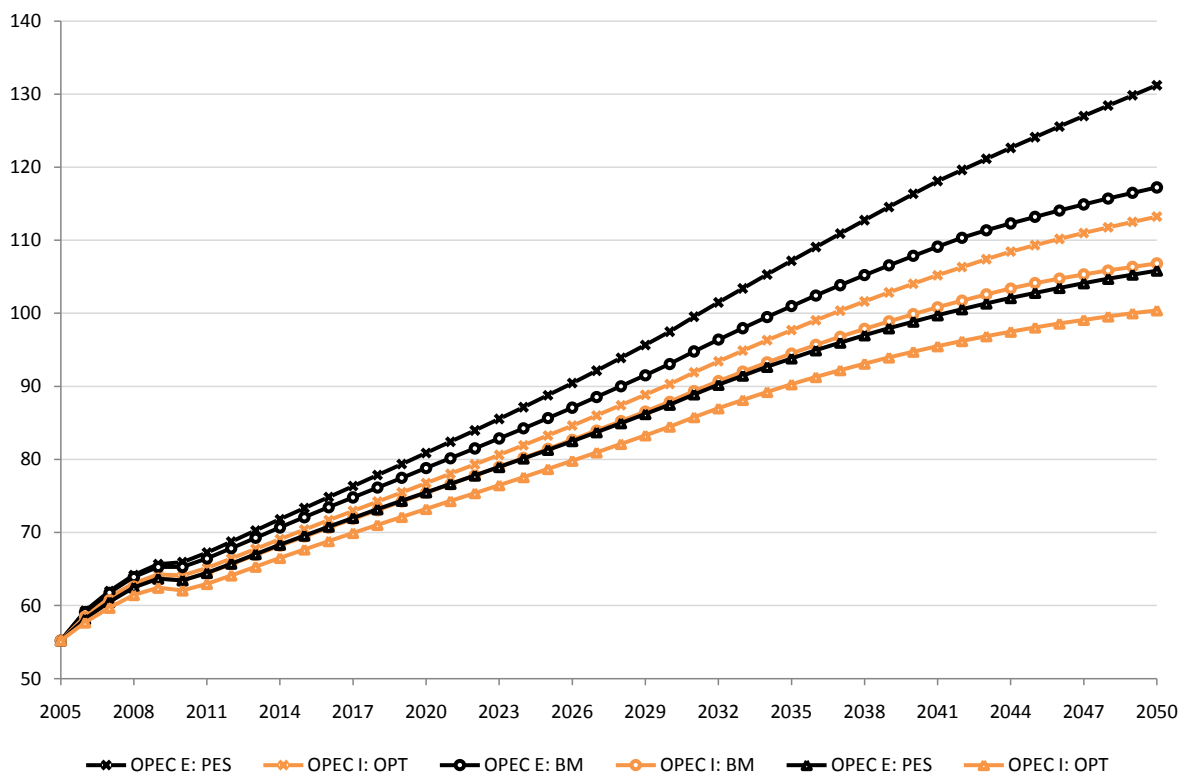

Figure 1: Crude oil prices in 2005 US \$

\section{Applying distinguished depletion rates}

Prices in figure 1 rise monotonically due to a strong demand for crude oil and increasing costs of extraction. As expected, prices are higher when OPEC is assumed to be an effective cartel; and as is evident, the strength of OPEC in influencing price highly depends on rates of reserve additions - consequently reserve levels - in the mature region: ${ }^{17}$. When rates of reserve additions in the mature regions are are low, an effective OPEC takes advantage of the market causing substantially higher prices as compared to a case where rates are high. From the demand function imposed on the market, this implies that OPEC collusion comes with significant reductions - at every point in time - in OPEC output, which consequently reduces global output. An approximate value of the impact of effective OPEC collusion on price by 2050 is as much as $\$ 17$ in 2005 prices $^{18}$.

In figure 2, trends in global crude oil production that are consistent with IEA 2008 trends are shown: production increases until 2030 without a peak. The impact of an

\footnotetext{
${ }^{16}$ Fattouh, 2007, Krichene, 2002 report price elasticities and income elasticities of demand for crude oil to be in the range of -0.0 to -0.08 , and 0.5 to greater than 1 , respectively.

${ }^{17}$ Given the strategic nature of the model, OPECs influence on price and production is also dependent on production in other regions other than the mature regions. However, since changes in production changes in those regions occur as a result of the change in rates of additions in the mature regions or assumptions about the OPEC market structure, we treat their influence as a secondary effect and do not report their responses in the analysis. In summary, however, such members increase production when either OPEC withholds or when rates of reserve additions are low in the mature regions.

${ }^{18}$ To see this, consider the difference in price, in 2050, between OPEC E: PES and OPEC E: OPT (approx. \$25), and OPEC I: PES and OPEC I: OPT (approx. \$ 8)
} 


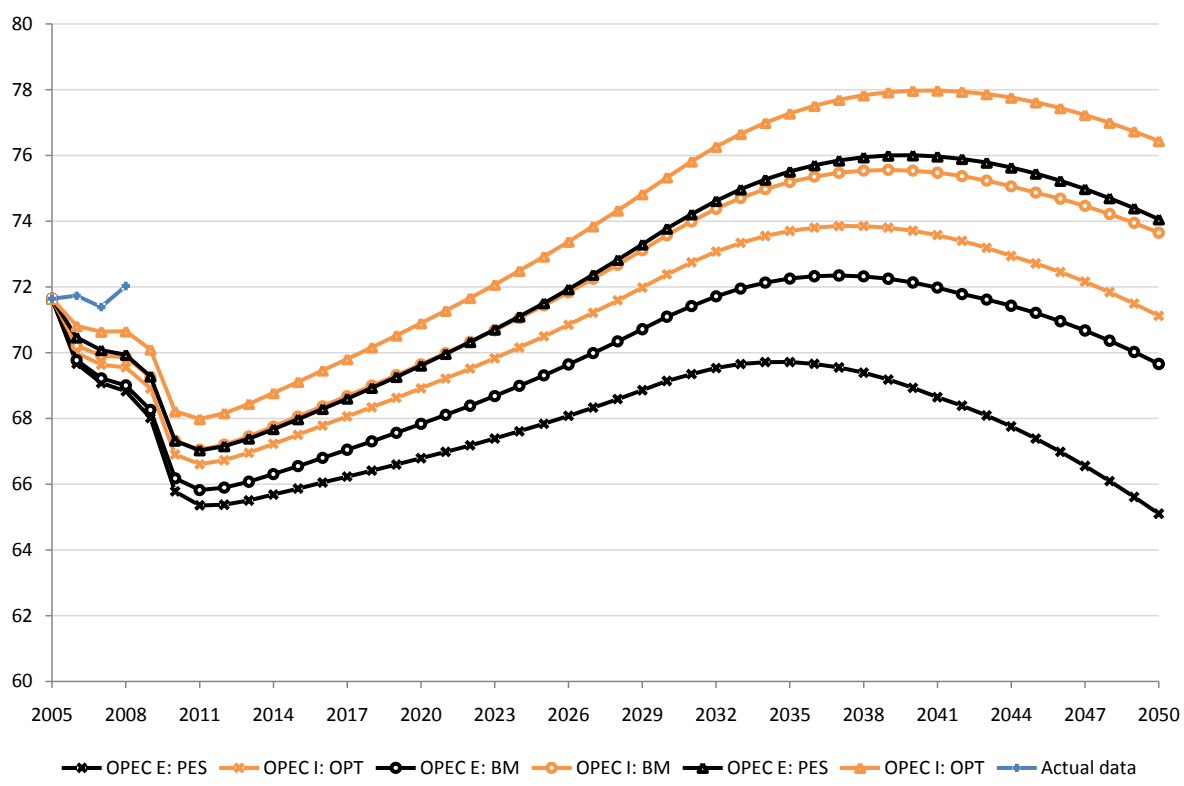

Figure 2: Global crude oil production in mbd

effective OPEC cartel on global crude oil production is to substantially lower supply. In the OPEC I: OPT scenario, production in 2030 reaches $75.3 \mathrm{mbd}$ which is close to the $75.2 \mathrm{mbd}$ that the IEA projects. In the corresponding OPEC E OPT scenario, however, production reaches a mere $73.5 \mathrm{mbd}$ due to a with holding strategy that OPEC adopts so as to earn a higher mark up on price. As economic theory predicts, the impact of a cartel - in this case an effective cartel - is to further hold back production thus pushing up prices. Higher prices, come with a higher mark up and it is this higher mark up that keeps the members in the cartel, otherwise, the cartel would collapse.

In all simulations, production increases up to peak after an initial slump that is due to a fall in demand associated with the recent (as per the time of writing) economic crisis. The timing of the peak is much earlier when reserve replacement levels in the mature regions are low, and, it comes at much lower level of global production when OPEC is effective because of OPECs with holding strategy. The peak window due to changes in the market structure is affected by reserve addition rates in the mature regions. For low reserve additions rates in the mature regions, the peak window is longer as compared to a case of high reserve additions. While this is evidence for (i) OPECs ability to strategically cause a much earlier peak in global oil production, more especially, when reserve additions rates are low in non-OPEC regions, it also shows that (ii) high reserve replacement levels in the mature regions lowers the benefits from strategy for the OPEC cartel. In fact, lowering OPECs initial depletion rates (thus its whole depletion path) by 5\%,20\%, and 30\% does not change its choice of peak date. This confirms that OPECs rather larger reserves allow it to substantially influence the market production trajectory from a strategic rather than a resource constrained position. 
Whereas Yang (2008) who investigates the impact of Alaskan Arctic National Wild Life Refuge (ANWR) exploration on OPEC finds that the market structure has a much stronger influence on OPEC behavior than exploration of the Arctic and that OPEC will reduce production whenever more resources are added from ANWR exploration. In our simulations we find that market structure and reserve additions are equally important in determining OPEC production. Unlike Yang (2008), we also find that OPEC can increase or decrease production for reserve additions in the mature regions (figure 3).

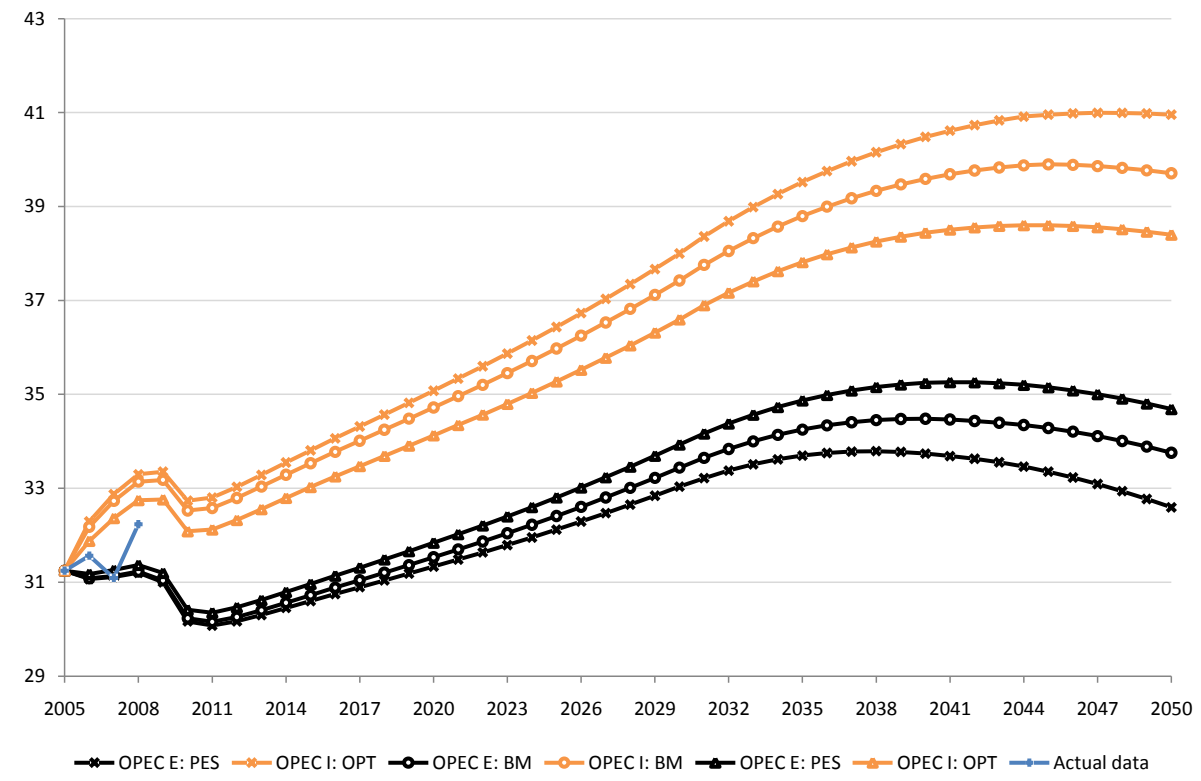

Figure 3: OPEC crude oil production in mbd

To start with, we re-state our earlier observation: the impact of market structure on OPEC is for OPEC to lower it production whenever it is an effective cartel and to extract at much higher levels whenever it is an ineffective cartel. These phenomina which was also mirrored in global crude oil production and price were deducible from figures 1 and 2 .

Now, for a given market structure, OPEC is completely capable of two opposite actions depending on whether it is an effective cartel or not. As an ineffective cartel, OPEC increases production for lower reserve replacement levels in the mature regions as would be expected of any rational producer-Yang (2008)'s finding. As an effective cartel, however, OPEC lowers production for lower reserve replacement levels in the mature regions. This action which is consistent with a true cartel, as seen earlier, hastens the date of peak in global oil production and lowers the level at which the peak occurs.

An effective cartel has considerably higher power, it will increase production only if its market power is being threatened: if there is a possibility that its market power will decline as a result of the fringe increasing production, the cartel will increase 
production. An ineffective cartel, on the other hand, is more interested in sales revenue than market power: market power is maintained not at the necessary minimum, but rather as a result of increasing sales revenue by increasing production. If the fringe increases production and the ineffective cartel also does the same, then higher output will drive down price leading to loss in revenues for the cartel. The cartel, therefore, will only increase production when the fringe's production is in decline.

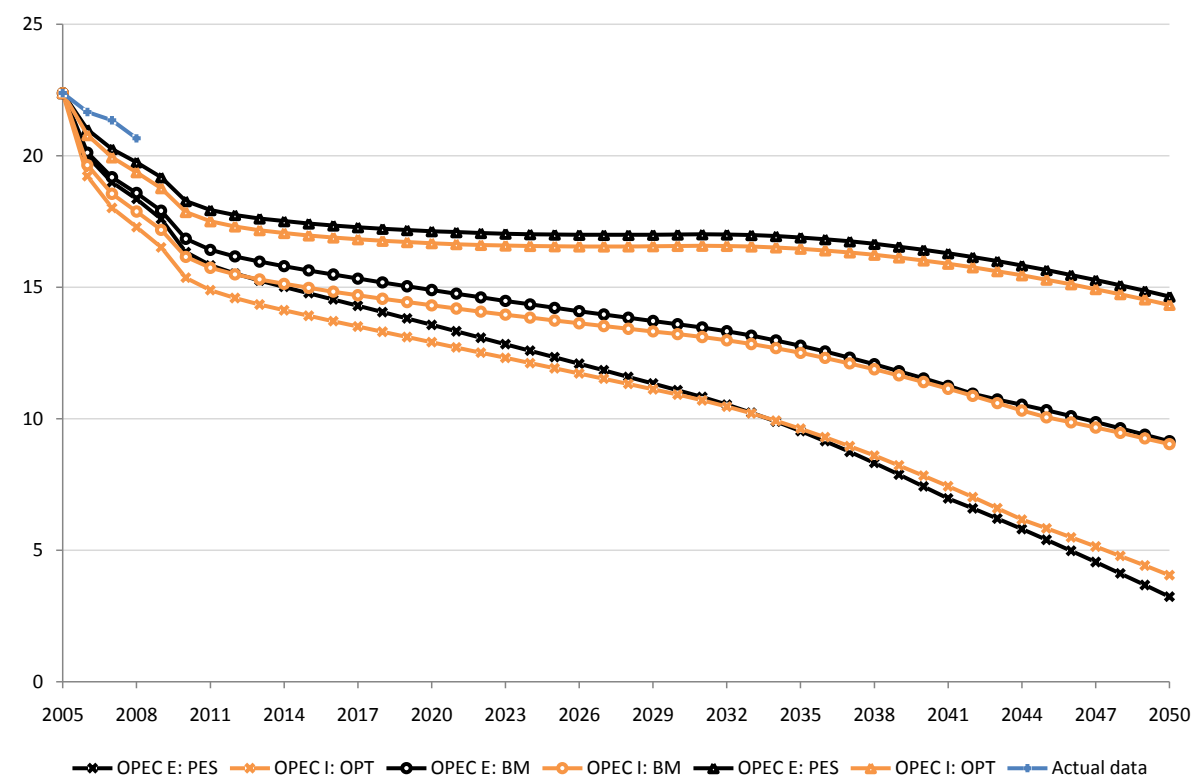

Figure 4: Crude oil production in mbd in the mature regions

Figure 4 shows total crude oil production from the mature regions. In spite of the substantial influence the market structure has on OPEC, mature regions increase production only marginally whenever OPEC withholds output. Instead, it is reserve replacement levels that highly determine output in the mature regions. Lower reserve replacement levels impose a lower limit on how much crude oil the mature regions can extract. This production limit, then implicitly imposes a limit on reserve additions leading to a faster decline in production. Exhaustability is a major problem in the mature regions leading to declining production even for more optimistic rates of reserve replacement.

Table 4 shows cumulative crude oil production for all regions. Crude oil production in the mature regions - and in general in non-OPEC regions - is seen to be more dependent on reserve additions as compared to OPEC production: by comparing cumulative crude oil production to initial proven reserves in table 3 , it is straight forward to see that non-OPEC producers extract one and half to three times their initial proven reserves whereas OPEC producers extract below or just above their initial proven reserves. For lower reserve replacement levels in the mature regions, non-OPEC producers who are not in the mature regions (FSU, LAM, and OTMA) increase production to 


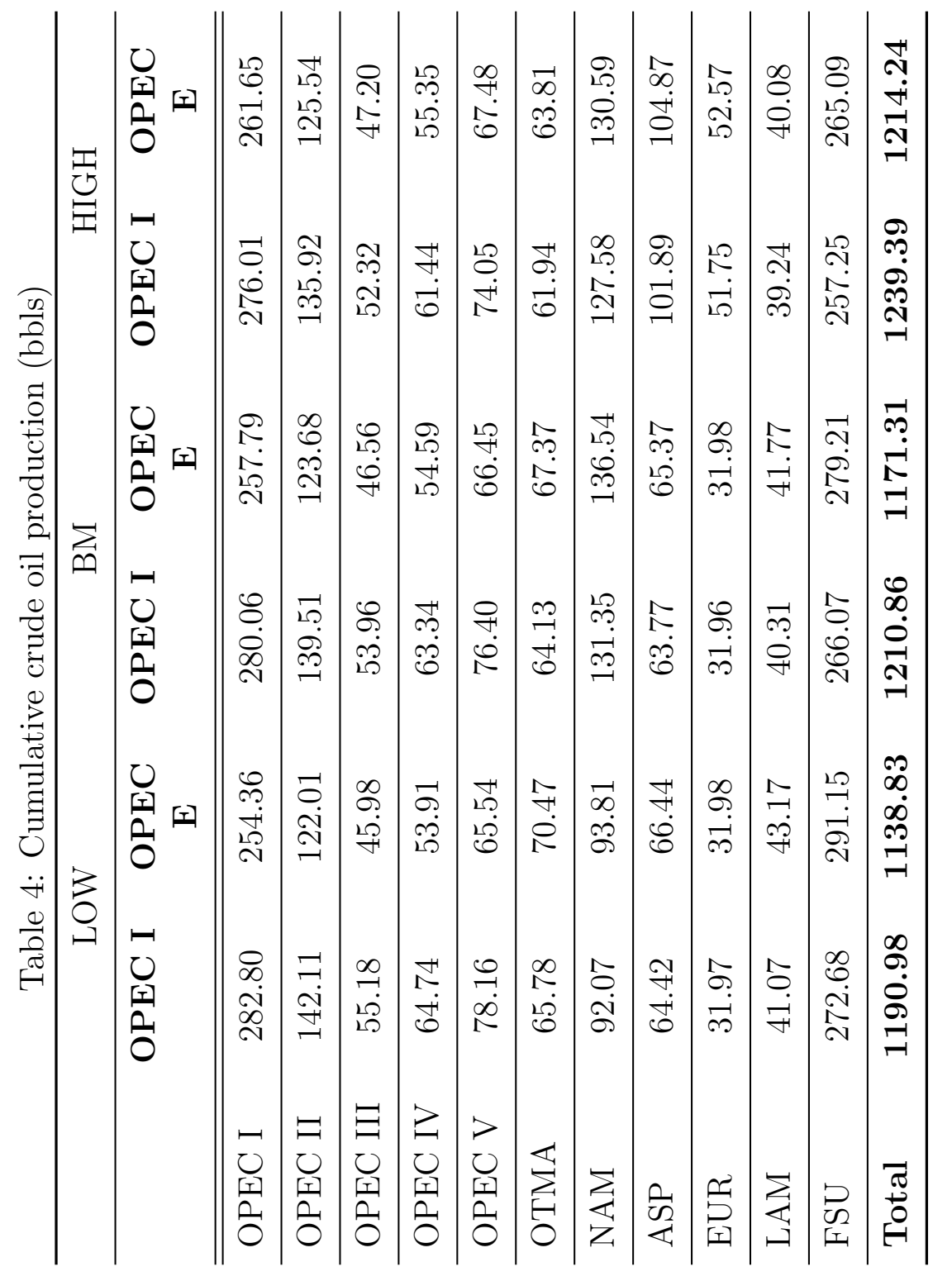


take advantage of higher prices caused by depletion in the mature regions. In addition, these producers increase production whenever OPEC withholds production due to effective collusion. Due to depletion constraints in these three regions, however, their increases in production due to the interaction of effective OPEC collusion and low reserve replacement in the mature, is insufficient to offset a decline in global crude oil production.

Since our results are based on econometric estimates of elasticities, it is possible that there is uncertainty that surrounds these parameters. For brevity we report results from a one sided sensitivity analysis even though the results do not alter our over all conclusions:

1. By lowering the fuel efficiency parameter ( $50 \%$ reduction to 0.06$)$ the total amount of crude oil extracted reduces by $10 \%$ across both market structures. On average, producers with larger resources (not necessarily OPEC producers) extract less in response to higher oil efficiency. Production from small producers is hardly affected since it is highly resource constrained.

2. Lowering price elasticity by $50 \%$, decreases production by about $6 \%$ in the ineffective case with even reductions across producers. In the effective case, however, production declines by about 10\%, moreover, OPEC members make larger reductions as compared to non-OPEC.

3. Increasing the rate of decline of reserve replacement rates by $50 \%$ (from 0.0015 to 0.003) hardly influences the total amount of resources extracted more especially for producers with large resource bases.

The proposed model was not intended for predicton of supply and prices, however, in comparing actual production levels to the simulated benchmark levels in figures 2, 3, and 4. it is evident that the projections for OPEC production are fairly accurate. Underprediction of production in the mature regions, however, results into an under-prediction of nearly the same magnitude in global oil production. From within the model, there are atleast three lucid explanation for this. First, the rates we use for simulating production in the mature regions are lower than the actual rates of depletion. Second, the use of a constant decline rate over the period 2005-2030 pushes production away from the initial periods. And third, the projected GDP levels following the economic crisis are much lower than actual realized levels. Due to data limitations, we were not able to correct these implications, but again, the values we use are representative and it eeasy to see that:

When rates of reserve replacement are higher than those we use, their impact will be to increase production in the mature regions which in turn increases simulated global crude oil production. In this case OPEC if an effective cartel will also increase production restoring production to the observed levels (at least approximately). The impact of a constant decline rate over the period 2005-2030, on the other hand, is to extend production as the immediate trade off of having to producer now is reduced. Gradually declining, rates therefore increase costs from later production forcing produces to 
extract more when rates of reserve replacement are still high. Finally, if the projected GDP levels following the economic crisis are actually higher, it is straight forward to see that producers in mature regions will increase production during this period resulting into higher total production than what we observe from the base case simulations.

Lastly, although the model provides insight and its results are robust, it is definite that it model does not account for all aspects in the crude oil industry. It is in some senses abstract and will require some extensions. These extensions include: introducing non-conventional oil resources that are purposed to play an increasingly greater role in the near future, e.g. coal to liquids, oil sands, oil shale and bio fuels; introducing capacity constraints in modeling oil production decisions; endogenizing the rates of reserve replacement; modeling regional specific demand responses i.e. transforming the model to a spatial model; solving the model sequentially over a number of periods rather than simultaneously and introducing arbitrageurs. All these exercises will help improve the realism of the model. For example, a) solving the model sequentially more realistically describes the inability of producers to plan extraction over very long periods of time, b) solving the model spatially allows for modeling of region specific demand related attributes that cannot be captured in a single demand function and c) arbitrageurs in the model would describe agents who hold obtain output from low price regions or low price points in time and sell elsewhere or at a later date so as to make gains.

\section{Conclusions}

We set out by developing a model that captures some significant aspects that are characteristic of global crude oil production: 1) the interdependence of crude oil supply on demand, 2) the determination of crude oil supply by its regional and geologic availability, 3) the strategic considerations of OPEC and non-OPEC producers and 4) the motivation for producers to exploit their oil reserves.

Using this model we established that although cumulative global crude oil production to 2050 could match current levels of proven reserves, substantial reserve additions will be required in mature crude oil regions - because of OPECs withholding strategyif inexorable declines in global crude oil production are to be avoided. For policy in mature regions, this requires that in-field and exploratory drilling, and research into improving recovery factors in oil wells be encouraged. Higher levels of reserve additions in the mature regions not only increase production in the mature regions, but also shift the probable date for peak oil and weaken the monopoly power of the OPEC cartel. In fact, as an effective cartel OPEC is seen to increase production for higher reserve replacement in the mature regions, rather than reduce it, as it would, if it were an ineffective cartel.

We also find that although OPECs leverage in influencing production is determined by both its market power and ability to control the rent it earns from extracting crude oil. Higher market share does not necessarily imply higher prices, but rather larger 
controls over the resource rent increase price and lower production substantially. In order to secure global crude oil production, in the short run at least, OPEC members, particularly those in the Middle East should be encouraged to liberalize their oil industry. This will not only increase production from OPEC regions but will also lower crude oil prices

Ultimately, however, such policies should come with fuel efficiency. If the proportion of oil used per unit of GDP is falling over time, the increase in price is smaller and the total amount of crude oil reserves extracted is less. With less crude oil extracted in total, it is definite that the pressure that will be put on the environment in search of new reserves will be less. 


\section{References}

M. A. Adelman and G. C. Watkins. Reserve prices and mineral resource theory. The Energy Journal, pages 1-16, 2008. Special issue.

P. Berg and S. Korte. Higher-order hubbert models for world oil production. Petroleum Science and Technology, 26(2):217-230, 2008.

Adam R. Brandt and Alexander E. Farell. Dynamics of the oil transition: Modelling capacity, costs and emissions. Submitted to Energy, 2009.

Colin J. Campbell and Jean H. Laherrère. The end of cheap oil. Scientific American, 278(3):78-83, 1998.

Alfred Cavallo. Hubbert's petroleum production model: an evaluation and implications for world oil production forecasts. Natural Resources Research, 13:211-221(11), December 2004.

Ujjayant Chakravorty, James Roumasset, and Kinping Tse. Endogenous substitution among energy resources and global warming. Journal of Political Economy, 105(6):1201-34, December 1997. URL http://ideas.repec.org/a/ucp/jpolec/ v105y1997i6p1201-34.html.

EIA. International energy outlook 2008. Technical report, Energy Information Administration, may 2008. URL http://www.eia.doe.gov/oiaf/ieo/pdf/0484(2006) . pdf.

Y. H. Farzin. The impact of oil price on additions to us proven reserves. Resource and Energy Economics, 23(3):271-292, July 2001. URL http://ideas.repec.org/ a/eee/resene/v23y2001i3p271-292.html.

Bassam Fattouh. The drivers of oil prices: The usefulness and limitations of nonstructural model, the demand-supply framework and informal approaches. Discussion Paper 71: Center of Financial and Management Studies, 2007.

Lars Lindholt Finn Roar Aune, Solveig Glomsrød and Knut Einar Rosendahl. Are high oil prices profitable for opec in the long run? Discussion Papers 416, Research Department of Statistics Norway, April 2005. URL http://ideas.repec.org/p/ ssb/dispap/416.html.

Dermot Gately. Opec's incentives for faster output growth. The Energy Journal, 25 (2):75-96, 2004. URL http://ideas.repec.org/a/aen/journl/2004v25-02-a04. html.

David L. Greene, Janet L. Hopson, and Jia Li. Have we run out of oil yet? oil peaking analysis from an optimist's perspective. Energy Policy, 34(5):515 - 531, 2006. ISSN 0301-4215. doi: DOI:10.1016/j.enpol.2005.11. 
025. URL http://www.sciencedirect.com/science/article/B6V2W-4HWX9XS-2/ 2/a0b7b4c641e4bbccf641a118758cb85b. Hong Kong Editorial Board meeting presentations.

Mikael Höök, Robert Hirsch, and Kjell Aleklett. Giant oil field decline rates and their influence on world oil production. Energy Policy, 37(6):2262-2272, June 2009. URL http://ideas.repec.org/a/eee/enepol/v37y2009i6p2262-2272.html.

M. King Hubbert. Nuclear energy and the fossil fuels. Drilling and Production Practice, 1956.

M. King Hubbert. Energy resources. Technical Report National Academy of Sciences Publication 1000-D, National Research Council, Washington D. C., Washington D.C, 1962.

IEA. World energy outlook. Technical report, Organisation for Economic and Cooperatice Development, 2008.

A. G Kemp and Stephene. Petroluem policy and prospects in the uk continental shelf. In Petroluem Industry Regulation within Stable States, volume 131-156. Ashgate Publishing Ltd, 2005.

Noureddine Krichene. World crude oil and natural gas: a demand and supply model. Energy Economics, 24(6):557 - 576, 2002. ISSN 0140-9883. doi: DOI: 10.1016/S0140-9883(02)00061-0. URL http://www.sciencedirect.com/science/ article/B6V7G-46MK68S-2/2/25aefc5a83bb83682bc347fc32a84eb1.

C.Y.C. Lin. Estimating strategic interactions in petroleum exploration. Energy Economics, 31(4):586-594, 2009.

Micheal C. Lynch. The new pessimism about petroluem resources: Debunking the hubbert model (and hubbert modelers). Minerals and Energy-Raw Materials report, 18(1):21-32, 2003.

Steve Hendrik Mohr and Geoffrey Michael Evans. Mathematical model forecasts year conventional oil will peak. Oil and Gas Journal, 105:45-50, 2007.

Steve Hendrik Mohr and Geoffrey Michael Evans. Peak oil: Testing hubbert's curve via theoretical modeling. Natural Resources Research, 17:1-11, 2008.

Peter Randon O'dell. Why Carbon Fuels Will Dominate the 21st Century's Global Energy Economy. Multi Science Publishing Co Ltd, 2004.

OPEC. The annual statistical bulletin, 2008.

M. Hashem Pesaran and Hossein Samiei. Forecastig ultimate resource recovery. International Journal of Forecasting, 11:543-555, 1995. 
Sandra Poncet. Long term growth prospects of the world economy: Horizon 2050, 2006. URL http://www.cepii.fr/anglaisgraph/workpap/pdf/2006/wp06-16.pdf.

Tobias Rehrl and Rainer Friedrich. Modelling long-term oil price and extraction with a hubbert approach: The LOPEX model. Energy Policy, 34:2413-2428, 2006.

H.H Rogner. An assessment of world hydrocarbon resources. Annual Review of Energy and the Environment, 22:217-262, 1997.

Russell S. Uhler. Costs and supply in petroleum exploration: The case of alberta. The Canadian Journal of Economics / Revue canadienne d'Economique, 9(1):72-90, 1976.

USGS. World petroleum assessment 2000, 2000a. URL http://pubs.usgs.gov/dds/ dds-060/.

USGS. The significance of field growth and the role of enhanced oil recovery. Technical report, United States Geological Survey, 2000b.

Mort Webster, Sergey Paltsev, and John Reilly. Autonomous efficiency improvement or income elasticity of energy demand: Does it matter? Energy Economics, 30(6):2785 - 2798, 2008. ISSN 0140-9883. doi: DOI:10.1016/j.eneco.2008.04. 004. URL http://www. sciencedirect.com/science/article/B6V7G-4SBHX3T-1/ 2/bdf4f1cd27d70015cee14b3c9901c6f7. Technological Change and the Environment.

Zili Yang. How does anwr exploration affect opec behavior? -a simulation study of an open-loop cournot-nash game. Energy Economics, 30(2):321 - 332, 2008. 


\section{A The Hamiltonian}

Let's assume that each of the $i$ suppliers has a single objective: profit maximization and for simplicity we ignore the resource exploration (reserve additions) function since we assume reserve addition to be exogenous, then, for the $i^{t h}$ supplier, where, $i=1, . . n$ and for $t, t=1,2, \ldots \ldots, T$ the time index, we define the producer's optimization problem as:

$$
\max _{\left\{q_{t}^{i}, E_{t}^{i}\right\}} \pi=\int_{0}^{\infty}\left(P\left(Q_{t}, Y_{t}, t\right) q_{t}^{i}-C\left(q_{t}^{i}, R_{t}^{i}, E_{t}^{i}, t\right)\right) e^{-\delta t}
$$

st

$$
\begin{gathered}
\dot{R}_{t}^{i}=-q_{t}^{i}+\dot{X}_{t}^{i} ; \dot{X}_{t}^{i}=f\left(E_{\tau}^{i}, X_{\tau}^{i}\right) \tau \leq t \\
R_{0}^{i}>0, q_{t}^{i} \geq 0 ; i=1, \ldots \ldots, n ; t=0, \ldots, \infty
\end{gathered}
$$

For, $P(Q)$, the market price, $R^{i}$, the resource stock (reserve), $q^{i}$, the amount of resource extracted (production), $R_{0}^{i}$, the initial resource stock and $R_{t}^{i}$, the change in reserves. $c($.$) is the cost function that the firm faces and it is governed by the following principles:$ $c_{q}>0, c_{q} q \geq 0, c_{R}<0$, and $c_{q} R<0$, which together with the constraints in 9 guarantee the existence of an optimal solution. $c_{q}>0$, requires the costs of extraction to increase with increasing resource extraction;. $c_{q}(q) \geq 0$, requires that marginal costs, $\left(c_{q}\right)$, also increase at a non decreasing rate $. c_{R}<0$, requires extraction costs to increase with resource depletion, i.e. as increasingly less of the resource remains, costs of extraction should increase. Finally $c_{q} R<0$ requires marginal costs to increase with resource depletion. This set of principles are as shown in Uhler [1976] are important assumptions for capturing physical depletion characteristics whenever resource extraction ensues. In addition they help guarantee the existence of an optimal solution.

To analytically solve the optimization problem using the Hamiltonian, we specify a form for the demand function, $P\left(Q_{t}\right)$, such that $\frac{\partial P}{\partial Q}<0$ where $Q_{t}=\sum_{i=1}^{n} q_{t}^{i}$.

The current value Hamiltonian will thus be defined as:

$$
H^{c, i}=P\left(Q_{t}\right) * q_{t}^{i}-C_{q}\left(q_{t}^{i}, R_{t-1}^{i}\right)-\mu^{i} q_{t}^{i}
$$

where $\mu^{i}=\lambda^{i} e^{-\delta t}$ for $\lambda^{i} \geq 0 . \quad \mu^{i}$ is commonly referred to as the current value scarcity rent, the current value shadow price, the current value economic rent, the current value marginal profit, discounted in situ value, or the current value opportunity cost in economic literature. It represents those additional benefits that a resource owner must receive in current value terms if she is to extract an extra unit of her resource - may also be viewed as an additional cost in terms of future benefits foregone due to extracting an extra unit of the resource today, also represented in current value terms.

Taking the derivative of the current value Hamiltonian with respect to extraction, the decision variable $u$, the resource stock and the Lagrange multiplier $\mu$ according to 


$$
\left.\begin{array}{c}
\frac{\delta H^{c}}{\delta u}=0 \\
\dot{\mu}=\rho \mu^{i}-\frac{\delta H^{c}}{\delta x} \\
\frac{\delta H^{c}}{\delta \mu}=\dot{x}
\end{array}\right\}
$$

We obtain:

$$
\begin{gathered}
P_{q}\left(Q_{t}\right) * q_{t}^{i}+P\left(Q_{t}\right)=c_{q}\left(q_{t}^{i}, R_{t-1}^{i}\right)+\mu^{i} \\
\dot{\mu}^{i}=\rho \mu^{i}-C_{R}\left(q_{t}^{i}, R_{t-1}^{i}\right) \\
\dot{R}^{i}=-q_{t}^{i}
\end{gathered}
$$

Consider 11, we re-write it as follows so as to make its economic explanation more relevant:

$$
P\left(Q_{t}\right)=\frac{1}{\left(1+n^{i}\right)}\left(C\left(q_{t}^{i}, R_{t-1}^{i}\right)+\mu^{i}\right)
$$

where, $n^{i}=-\frac{1}{\left|\varepsilon^{i}\right| z^{i}}$ for, $\varepsilon$, the elasticity of demand, $\left(\frac{\partial Q}{\partial P} * \frac{Q}{P}\right)$, and $z^{i}$ the elasticity of own output with respect to total output, $\left(\frac{\partial q^{i}}{\partial Q} * \frac{Q}{q^{i}}\right)$. 